ORIGINAL ARTICLE

\title{
Derivation of a clinical decision rule to guide the interhospital transfer of patients with blunt traumatic brain injury
}

\author{
C D Newgard, J R Hedges, J V Stone, B Lenfesty, B Diggs, M Arthur, R J Mullins
}

Emerg Med J 2005;22:855-860. doi: 10.1136/emj.2004.020206

\begin{abstract}
See end of article for authors' affiliations

.....................

Correspondence to: Craig D Newgard, Assistant Professor, Department of Emergency Medicine, Center for Policy and Research in Emergency Medicine, Oregon Health \& Science University, 3181 SW Sam Jackson Park Road, Mail Code CR-114, Portland, Oregon, USA 97239 3098; newgardc@ohsu. edu
\end{abstract}

Accepted for publication 13 March 2005

\begin{abstract}
Objective: To derive a clinical decision rule for people with traumatic brain injury (TBI) that enables early identification of patients requiring specialised trauma care.

Methods: We collected data from 1999 through 2003 on a retrospective cohort of consecutive people aged $18-65$ years with a serious head injury (AIS $\geqslant 3$ ), transported directly from the scene of injury, and evaluated in the ED. Information on 22 demographical, physiological, radiographic, and lab variables was collected. Resource based "high therapeutic intensity" measures occurring within 72 hours of ED arrival (the outcome measure) were identified a priori and included: neurosurgical intervention, exploratory laparotomy, intensive care interventions, or death. We used classification and regression tree analysis to derive and cross validate the decision rule.

Results: 504 consecutive trauma patients were identified as having a serious head injury: 246 (49\%) required at least one of the HTI measures. Five ED variables (GCS, respiratory rate, age, temperature, and pulse rate) identified subjects requiring at least one of the $\mathrm{HTI}$ measures with $94 \%$ sensitivity $(95 \% \mathrm{Cl} 91$ to $97 \%$ ) and $63 \%$ specificity (95\% Cl 57 to $69 \%$ ) in the derivation sample, and $90 \%$ sensitivity and $55 \%$ specificity using cross validation.

Conclusions: This decision rule identified among a cohort of head injured patients evaluated in the ED the majority of those who urgently required specialised trauma care. The rule will require prospective validation in injured people presenting to non-tertiary care hospitals before implementation can be recommended.
\end{abstract}

$\mathrm{T}$ here is a growing body of literature assessing appropriate criteria for both out of hospital triage to a tertiary trauma centre, ${ }^{1-23}$ as well as the need for full trauma team activation after transportation to a trauma centre. ${ }^{24-29}$ However, there is a paucity of studies deriving criteria for the interhospital transfer of injured patients initially presenting to non-tertiary care facilities. In rural hospital emergency departments (EDs), early identification of patients requiring interhospital transfer for higher level of care services is a critical component of trauma systems that aspire to assure optimal care to both rural and urban citizens. Objective, easily applied interhospital transfer guidelines are needed to guide the early identification and expeditious transfer of people to hospitals that are capable of delivering specialised trauma care.

Patients with traumatic brain injury (TBI) are a subset of injured patients that may have special relevance to the issue of early identification and expeditious transfer for higher level of care services. Patients with TBI often require neurosurgical and intensive care in hospitals with specialised resources. Patients with TBI are at greater risk for adverse outcome if they are deprived of appropriate care in the acute setting, ${ }^{30} 31$ and delays in initiating definitive neurosurgical care for patients requiring interhospital transfer in regions with long ground travel times are common. ${ }^{32}$ Despite the potential seriousness of TBI, not all individuals who sustain a head injury will require higher level of care resources. In many circumstances, the decision to transfer a patient must balance the costs, risks, patient preferences, and resources required for transport with the procedures and treatments that will be provided when he/she arrives at the tertiary care facility. Relying exclusively upon diagnostic criteria to identify patients for interhospital transfer is not ideal, as all injuries may not be recognised during the initial evaluation. We reason that there is a need to develop data driven guidelines, using information readily available during the initial ED evaluation, to identify those people likely to require specialised care without missing patients who will need such services.

In this study, our objective was to derive a clinical decision rule that could be applied to a subset of high risk peoplethat is, people with serious TBI-to identify the group of patients requiring specialised tertiary care resources, using variables readily available to healthcare providers during the initial ED evaluation.

\section{METHODS}

\section{Study design and setting}

We collected data on a retrospective cohort of patients presenting to a level I trauma centre with serious blunt head injury from January 1999 through August 2003. Trained medical record abstractors collected data using a structured data collection instrument. The Oregon Health \& Science University (Portland, Oregon, USA) Institutional Review Board approved this study and waived the requirement for informed consent.

\section{Patients}

Consecutive trauma patients aged 18-65 years, transported directly from the scene of injury, evaluated in the ED of a level I trauma centre, and retrospectively identified from our hospital trauma registry as having a "serious" head injury

Abbreviations: AIS, Abbreviated Injury Scale; ED, emergency department; GCS, Glasgow Coma Scale; HTI, high therapeutic intensity; INR, international normalised ratio; TBI, traumatic brain injury 
(Abbreviated Injury Scale (AIS) $\geqslant 3$ ) were included in the analysis. The AIS for a given injury ranges from 1 (minor) to 6 (non-survivable) and a score of 3 or more represents a "serious" injury. ${ }^{33}$ Many patients had additional serious injuries. Children $(<18$ years) and older adults ( $>65$ years) were excluded as the project was initiated to collect information on TBI patients in a working age population and because transfer decisions in these two age groups often involve additional factors-for example, availability of paediatric inpatient care for injured children, and comorbidities and end of life issues in an older population. Because of the difficulty in collecting data from the initial hospital evaluation for transfer patients and the potential for spectrum bias in such patients, people initially evaluated at an outside hospital and subsequently transferred to our ED were excluded. Patients with penetrating head injury and people that died within 90 minutes of ED arrival were also excluded.

\section{Main outcome measure}

In conjunction with our hospital's trauma surgeons and emergency physicians, we a priori identified several resource based "high therapeutic intensity" (HTI) measures undertaken within 72 hours of presentation: neurosurgical intervention-for example, craniotomy, ventriculostomy, or placement of an intracranial pressure monitor- exploratory laparotomy, intensive care measures (transfusion $\geqslant 6$ units of packed red blood cells or infusion of vasoactive agents), or death.

\section{Variables considered for the decision rule}

We collected information on 22 variables routinely assessed and available to clinicians in most ED practice settings. Although this study was conducted using data from patients transported directly to a level I trauma centre, we considered clinical variables applicable to injured people presenting to non-trauma centres or rural hospitals with limited resources. These variables included patient demographics (age, race); comorbid conditions (chronic obstructive pulmonary disease, diabetes, end stage liver disease, coronary artery disease, or pregnancy); out of hospital physiological findings (systolic blood pressure, pulse rate, respiratory rate, Glasgow Coma Scale (GCS) score, pulse oximetry); initial ED physiological findings (systolic blood pressure, pulse rate, respiratory rate, GCS, pulse oximetry, temperature); intubation (prior to hospital arrival or within the first 10 minutes in the ED); initial lab values (haematocrit $(\%)$, bicarbonate $(\mathrm{mmol} / \mathrm{L})$, international normalised ratio (INR)); chest radiograph (normal or abnormal); exam findings (unilateral dilated pupil, alcohol intoxication); and emergency medical services traumatic arrest. A chest radiograph was considered "abnormal" if any of the following were noted on the final attending radiology reading: rib fracture(s), abnormal aorta, presence of a chest tube, diaphragmatic hernia, pleural fluid, infiltrate/ atelectasis, pneumothorax/haemothorax, subcutaneous emphysema, or pulmonary contusion.

To ensure adherence to quality standards for chart review, we used trained medical record abstractors who were blinded to the study objective. All variables of interest were explicitly defined a priori on a standardised data collection instrument. We held monthly meetings with the chart abstractors during the period of data collection and routinely checked interrater reliability measures for data abstraction to ensure consistency of data abstraction and data entry. ${ }^{34}$

\section{Statistical analysis}

We used classification and regression tree analysis $\left(\mathrm{CART}^{\circledR}\right.$ version 4.0, Salford Systems, San Diego, California, USA) to create a decision tree to separate people requiring a HTI measure in the first 72 hours from those not requiring such intensive measures. CART analysis is a non-parametric method of analysis used to classify observations, based on a large number of possible predictive variables, and is well suited at identifying complex, higher level interactions among variables. ${ }^{35}$ Misclassification costs and tree complexity parameters were empirically selected to generate a highly sensitive $(\geqslant 90 \%)$ and practical (3-6 decision nodes) decision tree with moderate specificity $(\geqslant 50 \%)$ and clinical sensibility (face validity). The sensitivity and specificity of the decision tree were calculated using 10 -fold cross validation, ${ }^{36-38}$ providing a less biased, more conservative, estimate of rule performance.

\section{RESULTS}

There were 504 consecutive trauma patients evaluated in the ED and identified as having a serious head injury from January 1999 through August 2003. No subjects were excluded for missing information. Characteristics of the sample in order of relative importance, as defined by the CART analyses, are listed in table 1. There were 246 subjects (49\%) who required at least one of the HTI measures (neurosurgical intervention, laparotomy, packed red blood cell transfusion $\geqslant 6$ units, vasopressor support, or death) within the first 72 hours after ED presentation (table 2).

The decision tree derived to identify subjects with head injury requiring timely HTI included five variables (initial ED GCS, initial ED respiratory rate, patient age, initial ED temperature, and initial ED pulse rate) (fig 1). For the derivation sample, the decision rule was $94 \%$ sensitive (95\% confidence interval (CI) 91 to $97 \%$ ) and 63\% specific (95\% CI 57 to $69 \%$ ) (table 3 ). Cross validation analysis of the decision tree yielded an estimated sensitivity of $90 \%$ and specificity of $55 \%$ for identifying subjects requiring at least one of the HTI measures (table 3).

\section{DISCUSSION}

In this study, we derive a clinical decision rule to detect, among a cohort of patients with serious head injury, those people who required specialised trauma care interventions or died within 72 hours of ED presentation. The study was restricted to a high risk subset of trauma patients-that is, subjects with head injury with AIS $\geqslant 3$-because we reasoned it would be prudent to focus our initial efforts on developing a rule using a relatively homogenous and high risk group of patients who had a high prevalence of specialised interventions. We view this decision rule as a preliminary, but valuable first step in developing an accurate and broadly generalisable interhospital decision rule to be used in nontertiary care settings for injured persons.

Although previous studies have shown transfer patients to be seriously injured, critically ill, and at high risk for medical complications and mortality, ${ }^{39-41}$ there are several problems with current interhospital transfer practices in the United States. We have previously demonstrated non-clinical factors - that is, gender, age, and level of initial hospital-to be independently associated with higher level of care transfer after adjusting for injury severity and physiological information. ${ }^{41}$ In addition, many trauma systems promulgate guidelines that are primarily injury based and reflect expert opinion rather than evidence based or data driven criteria. Guidelines based solely upon injury diagnoses conflict with the suggestion that a patient's need for tertiary care resources correlates poorly with injury type or severity. ${ }^{16} 1742$ Furthermore, the established diagnoses in a patient first being evaluated in the ED of a rural hospital may be in error or incomplete because diagnostic testing is limited because of lack of resources-for example, computed tomography and emergency ultrasonography-and because of the healthcare 
Table 1 Description of characteristics for people with traumatic brain injury in order of relative importance to deriving the clinical decision rule

\begin{tabular}{|c|c|c|c|c|c|}
\hline \multirow[b]{2}{*}{ Median ED GCS $\ddagger$} & \multirow{2}{*}{$\begin{array}{l}\begin{array}{l}\text { Variable } \\
\text { importance* }\end{array} \\
100\end{array}$} & \multicolumn{2}{|c|}{$\begin{array}{l}\text { Subjects not requiring } \\
\text { HTI measures } n=258\end{array}$} & \multicolumn{2}{|c|}{$\begin{array}{l}\text { Subjects requiring HTI } \\
\text { measures† } n=246\end{array}$} \\
\hline & & 15 & $(14-15)$ & 3 & $(3-3)$ \\
\hline Median EMS GCS & 46.0 & 14 & $(12-15)$ & 6 & $(3-12)$ \\
\hline $\begin{array}{l}\text { Median ED respiratory rate (breaths/ } \\
\text { min) }\end{array}$ & 14.5 & 20 & $(16-22)$ & 20 & $(16-26)$ \\
\hline Median ED pulse rate (beats/min) & 11.8 & 91 & $(80-104)$ & 101 & $(86-116)$ \\
\hline Abnormal chest radiograph & 11.1 & 62 & $(24 \%)$ & 127 & $(52 \%)$ \\
\hline Median ED temperature $\left({ }^{\circ} \mathrm{C}\right)$ & 6.6 & 36.2 & $(36.0-36.6)$ & 35.9 & $(35.2-36.2)$ \\
\hline $\begin{array}{l}\text { Median EMS respiratory rate (breaths/ } \\
\text { min) }\end{array}$ & / 6.2 & 18 & $(16-20)$ & 18 & $(14-24)$ \\
\hline Median age (years) & 5.9 & 39.5 & $(26-50)$ & 36 & $(24-47)$ \\
\hline Median EMS pulse rate (beats/min) & 5.0 & 92 & $(80-102)$ & 96 & $(80-115)$ \\
\hline Median initial INR & 3.2 & 1.0 & $(0.9-1.1)$ & 1.0 & $(1.0-1.2)$ \\
\hline Median EMS pulse oximetry (\%) & 1.6 & 99 & $(98-100)$ & 98 & $(95-99)$ \\
\hline Median initial haematocrit (\%) & 1.4 & 40 & $(37-43)$ & 38 & $(34-42)$ \\
\hline Median ED pulse oximetry (\%) & 1.3 & 98 & (96-100) & 99 & $(96-100)$ \\
\hline Non-white race & 0 & 37 & $(14 \%)$ & 35 & $(14 \%)$ \\
\hline Comorbid condition & 0 & 21 & $(8 \%)$ & 9 & $(4 \%)$ \\
\hline $\begin{array}{l}\text { Median initial serum bicarbonate } \\
\text { (mmol/L) }\end{array}$ & 0 & 23 & $(20-24)$ & 20 & $(17-22)$ \\
\hline EMS arrest & 0 & 2 & $(1 \%)$ & 6 & $(2 \%)$ \\
\hline $\begin{array}{l}\text { EMS systolic blood pressure }< \\
90 \mathrm{mmHg}\end{array}$ & 0 & 12 & $(5 \%)$ & 36 & $(15 \%)$ \\
\hline ED systolic blood pressure $<90 \mathrm{mmHg}$ & 0 & 6 & $(2 \%)$ & 23 & $(9 \%)$ \\
\hline Dilated unilateral pupil & 0 & 19 & $(7 \%)$ & 39 & (16\%) \\
\hline Alcohol intoxication & 0 & 108 & $(42 \%)$ & 102 & (41\%) \\
\hline \multicolumn{6}{|c|}{$\begin{array}{l}\text { *The relative importance of each variable ranges from } 0-100 \text { (the most important variable in the decision tree } \\
\text { derivation process has a score of 100) and represents a quantification of how often a given variable was used as a } \\
\text { primary or surrogate splitter in the CART }{ }^{\circledR} \text { tree building process. Variables with a score of } 0 \text { are listed in no } \\
\text { particular order. } \\
\text { tProportions are calculated based on the total number of subjects in each group, by column. The median and } \\
\text { interquartile range (IQR) is presented for continuous variables. } \\
\text { Ilntubation is included in the ED GCS variable (patients intubated in the field or in the first } 10 \text { minutes of ED arrival } \\
\text { were assigned an ED GCS of 3) and was consequently left out of the analysis as an independent covariate. Analysis } \\
\text { with intubation included did not change the results. } \\
\text { ED, emergency department; EMS, ; GCS, Glasgow Coma Score; HTI, high therapeutic intensity; INR, international } \\
\text { normalised ratio }\end{array}$} \\
\hline
\end{tabular}

providers' initial emphasis on establishing only the life and limb threatening diagnoses. Some regions in the United States lack any standardised policy for interhospital transfer. ${ }^{43}$ Despite the high prevalence and acuity of these patients, many systems continue to rely on physician judgment to determine the need for higher level of care transfer, which is variable and subjective.

The decision rule developed in this study is unique for several reasons. This is the first decision rule targeted for the identification of interhospital transfer patients (specifically, trauma patients with TBI requiring specialised trauma care services). In areas with regionalisation of resources, the interhospital transfer process plays a critical role in providing

Table 2 Components of the high therapeutic intensity (HTI) outcome measure (within 72 hours of initial emergency department presentation)

\begin{tabular}{lrl}
\hline & People & $\begin{array}{l}\text { \% People with HTI } \\
\text { (n=246) }\end{array}$ \\
\hline $\begin{array}{l}\text { HTI outcome measures: } \\
\text { Intracranial pressure monitor }\end{array}$ & 185 & $(75 \%)$ \\
$\begin{array}{l}\text { placement } \\
\text { Ventriculostomy }\end{array}$ & 40 & $(16 \%)$ \\
$\begin{array}{l}\text { Craniotomy } \\
\text { Laparotomy }\end{array}$ & 101 & $(41 \%)$ \\
$\begin{array}{l}\text { Vasopressors used } \\
\text { Packed red blood cell transfusion }\end{array}$ & 30 & $(12 \%)$ \\
$\geqslant 6$ units & 94 & $(38 \%)$ \\
Death & 40 & $(16 \%)$ \\
\hline
\end{tabular}

specialised care to high risk patients who are initially evaluated at non-trauma centres. Although some trauma systems are able to triage patients to tertiary facilities directly from the field, this may not be realistic in other systems, particularly in areas with long transport distances. Many patients injured in rural areas in the United States are seen and stabilised initially at non-tertiary care centres then subsequently transferred for additional care as needed. In addition, there are large variations in the level of available services at United States non-trauma hospitals. For nontertiary care hospitals with some surgical and intensive care unit capacity, the decision rule derived here may serve to simply identify high need patients quickly, with the decision to transfer based on resource availability and hospital capacity, whereas centres without any surgical or intensive care capacity may seek to immediately transfer all patients identified by this rule. It should also be noted that some situations may not warrant transfer despite a patient meeting pre-specified criteria-for example, where further care is felt to be futile or in which a patient is too unstable to survive transport to another hospital. In situations where a patient may not be "stable" enough for transfer, we believe such patients will need to be assessed individually, as many additional factors - for example, distance to a tertiary trauma centre, how "unstable" a given patient is, transport options available, urgency of resource need, whether additional resuscitation would improve status for transfer, and so forth-may affect the decision to transfer.

This rule was designed to identify subjects requiring high therapeutic interventions-that is, specialised tertiary care resources-rather than simply identifying patients who 


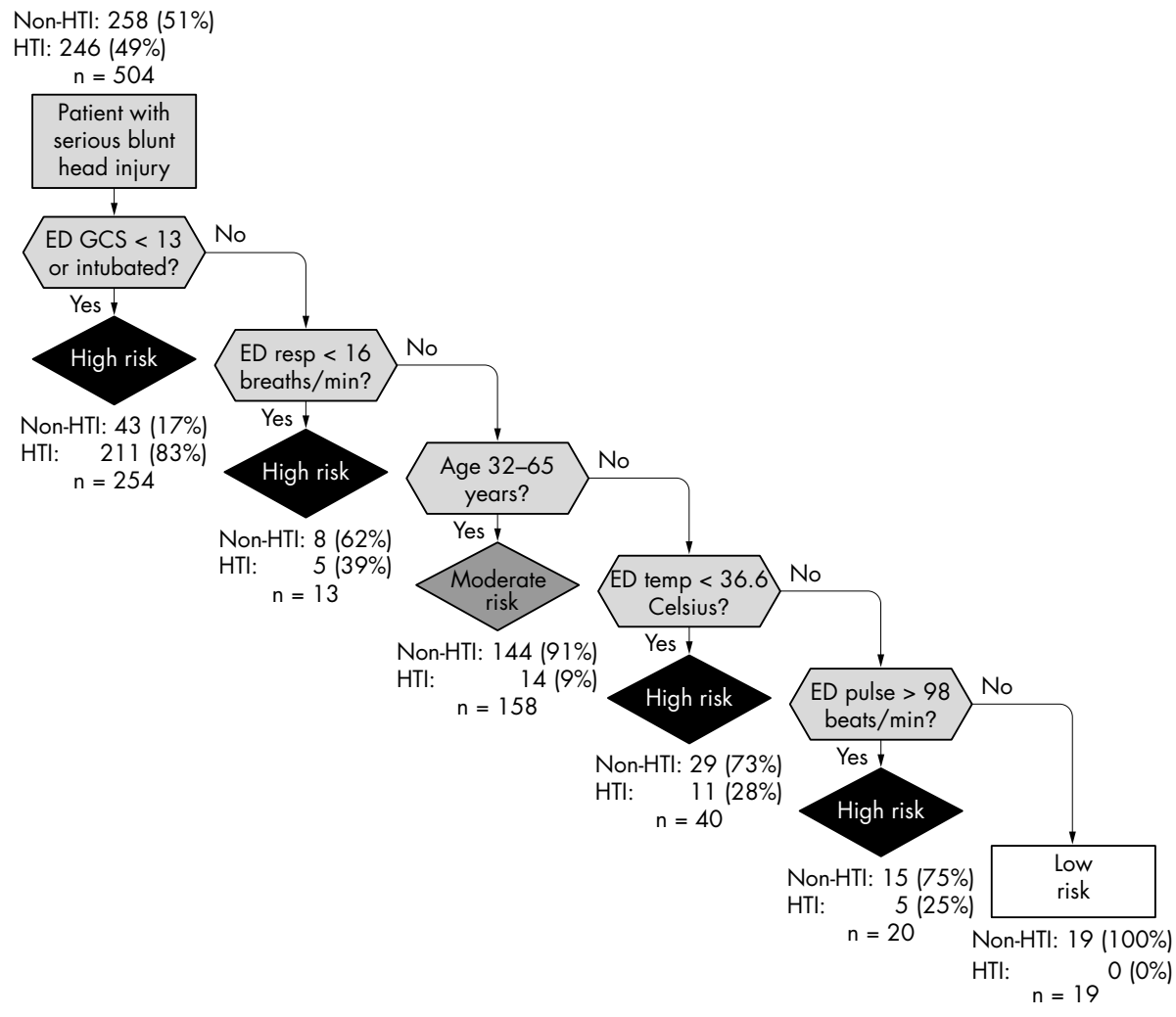

Figure 1 Decision tree for predicting patients (18-65 years) with head injury requiring high therapeutic intensity interventions (neurosurgical intervention, exploratory laparotomy, vasopressor support, packed red blood cell transtusion $\geqslant 6$ units, or death), within 72 hours of the initial emergency department presentation. ED, emergency department; GCS, Glasgow Coma Score; HTI, high therapeutic intensity.

would be categorised as seriously injured based upon the number and severity of their injuries - for example, the Injury Severity Score. All of the patients included in our sample had a "serious" head injury (AIS $\geqslant 3$ ), which may be regarded by some as an adequate reason to transfer the patient for higher level services without further consideration; however, only half of these patients required one of the HTI interventions or died in the first 72 hours after presentation. As it remains unclear which patients are most likely to benefit from interhospital transfer to a tertiary trauma centre, we elected to use a resource based definition of trauma care need, consistent with allocation of resources for acute care in a rural trauma system.

Finally, this is the first decision rule assessing both EMS and initial ED information to identify a subset of patients for interhospital transfer. The sequential decision points of the CART analyses are sensible and intuitive. Similar to several

Table 3 Performance measures of the clinical decision rule

\begin{tabular}{lccc}
\hline & \multicolumn{2}{l}{ HTI outcome* } & \\
\cline { 2 - 4 } & $\begin{array}{l}\text { Derivation } \\
\text { sample }\end{array}$ & $(95 \% \mathrm{Cl})$ & $\begin{array}{l}\text { Cross } \\
\text { validation }\end{array}$ \\
\hline Sensitivity & $94 \%$ & $(91-97 \%)$ & $90 \%$ \\
Specificity & $63 \%$ & $(57-69 \%)$ & $55 \%$ \\
Positive predictive value & $71 \%$ & $(66-76 \%)$ & $66 \%$ \\
Negative predictive value & $92 \%$ & $(87-96 \%)$ & $85 \%$ \\
Positive likelihood ratio & 2.56 & $(2.18-3.01)$ & 2.00 \\
Negative likelihood ratio & 0.09 & $(0.05-0.15)$ & 0.19 \\
\hline
\end{tabular}

*High therapeutic intensity (HTI) outcome: neurosurgery, laparotomy, vasopressor support, transfusion $\geqslant 6$ units of packed red blood cells, or death within 72 hours of ED presentation. previous studies, GCS score was important in identifying patients ultimately requiring HTI. ${ }^{815-17} 2944$ Using this decision rule, patients with serious head injuries and GCS $<13$ in the ED (including intubated patients) are at very high risk for requiring one of the HTI measures and will likely require care in a specialised facility. For those patients with a GCS 13-15, a respiratory rate $<16$ also identified a high risk group of patients likely to require a HTI measure, which supports findings in previous studies. ${ }^{6} 16182345$ For patients with a relatively normal GCS and respiratory rate $\geqslant 16$, being 32-65 years was identified as a moderate risk category, which could be watched closely in the ED and subsequently transferred if signs of shock or mental status changes developed. Because our sample was limited to patients aged 18-65 years, we would expect head injured patients over 65 years to represent another high risk group, though validation with a broader sample would be needed to assess this possibility. Younger patients (18-31 years) with any degree of hypothermia (ED temp $<36.6^{\circ} \mathrm{C}$ ) or tachycardia (ED pulse rate $>98$ beats/ minute), reflective of some degree of physiological derangement, represent additional high risk groups. The low risk group consisted of head injured patients with a relatively normal GCS score (13-15) and respiratory rate $(\geqslant 16)$, younger age (18-31 years), normothermia, and a normal pulse rate.

Ideally, a decision rule of this type would be $100 \%$ sensitive in identifying subjects requiring tertiary trauma care; however, the sensitivity must be balanced with specificity and the "cost" of missing patients requiring higher level of care services. Decisions regarding acceptable sensitivity and specificity for identifying people requiring higher level of care services will ultimately depend on resource availability, the difficulties inherent in the processes and circumstances of transferring patients, the number of tertiary trauma centres 
available, and other priorities in a given region. The efficiency of a trauma system and improved health outcomes could potentially be increased by application of an objective decision rule that reduces the number of needless or inappropriate transfers, while capturing those patients requiring timely tertiary care who would not have otherwise been transferred.

\section{LIMITATIONS}

The main limitations of this study are the retrospective study design and fairly restrictive inclusion criteria focusing on a high risk group of working age adults. We studied patients of a specific age range having a serious head injury and presenting to a level 1 trauma centre. Ideally, such a study would prospectively sample patients from non-tertiary care centres-for example, rural hospitals-where such a clinical decision rule is likely to be most useful and to have the biggest impact on patient care. We view these results as the initial step in developing an effective rule with broad generalisability that guides clinicians in the interhospital transfer of injured patients. As with all derived decision rules, this rule requires prospective validation, particularly in a population of injured patients first being evaluated at nontertiary hospitals.

Although implementation of state wide trauma systems has improved the outcomes of seriously injured patients, ${ }^{46-52}$ the health outcome benefit of certain patient subgroups within trauma systems-for example, interhospital transfer patients - has yet to be established. We used a resource based definition to identify patients requiring tertiary care services in this study, although the ideal outcome for such a rule would be the patient subgroup most likely to benefit-that is, to have improved health outcomes-from higher level of care transfer. Until the characteristics of this patient group are established, we must use alternative definitions (such as processes of care) for patients requiring higher level of care services. Implicit in our definition of the resource based outcome is the assumption that patients undergoing these specialised services actually needed them and that they derived some outcome benefit by receiving these services at a tertiary care centre. We do not know whether withholding resources-for example, intracranial pressure monitorswould have adversely impacted outcome in all patients.

Finally, the ability to reliably collect data for all such variables - that is, interrater reliability-and the accuracy of the rule when applied to patients presenting to non-trauma centres will need to be assessed prospectively.

\section{CONCLUSIONS}

Using a combination of physiological and demographical information, we derived a decision rule that identified most TBI people in the derivation sample requiring timely specialised trauma care. The potential merit of this interhospital transfer rule rests in the ability to quickly identify brain injured patients who will require specialised trauma care while avoiding transfers that are unlikely to need timely tertiary care services. Prospective studies to validate this rule in injured patients presenting to non-trauma facilities and rural hospitals are needed.

\section{ACKNOWLEDGMENTS}

We thank Alice Rogers and Mauretta Christensen for their help in abstracting patient records for this study.

\section{Authors' affiliations}

C D Newgard, J R Hedges, Center for Policy and Research in Emergency Medicine, Department of Emergency Medicine, Oregon Health \& Science University, Portland, Oregon, USA

J V Stone, B Lenfesty, B Diggs, M Arthur, R J Mullins, Department of
Surgery, Trauma/Critical Care Section, Oregon Health \& Science University, Portland, Oregon, USA

Funding: this research was supported by grant R49/CCR-006283 from the U.S. Public Health Service, Centers for Disease Control and Prevention, National Center for Injury Prevention and Control, Atlanta, Georgia, USA.

Competing interests: none declared

The Oregon Health \& Science University (Portland, Oregon, USA) Institutional Review Board approved this study and waived the requirement for informed consent.

\section{REFERENCES}

1 Tepas JJ, Ramenofsky ML, Mollitt DL, et al. The pediatric trauma score as a predictor of injury severity: An objective assessment. J Trauma 1988;28:425-9.

2 Eichelberger MR, Gotschall CS, Sacco WJ, et al. A comparison of the trauma score, the revised trauma score, and the pediatric trauma score. Ann Emerg Med 1989;18:1053-8.

3 Chan BSH, Walker PJ, Cass DT. Urban trauma: An analysis of 1,116 paediatric cases. J Trauma 1989;29:1540-7.

4 Kaufmann CR, Maier RV, Rivara FP, et al. Evaluation of the pediatric trauma score. JAMA 1990;263:69-72.

5 Phillips S, Rond PC, Kelly SM, et al. The need for pediatric-specific triage criteria: results from the Florida trauma triage study. Pediatric Emergency Care 1996; 12:394-8.

6 Engum SA, Mitchell MK, Scherer LR, et al. Prehospital triage in the injured pediatric patient. J Pediatr Surg 2000;35:82-7.

7 Nayduch DA, Moylan J, Rutledge R, et al. Comparison of the ability of adult and pediatric trauma scores to predict pediatric outcome following major trauma. J Trauma 1991;31(4):452-8.

8 Cottington EM, Young JC, Shufflebarger CM, et al. The utility of physiologic status, injury site, and injury mechanism in identifying patients with major trauma. J Trauma 1988;28:305-11.

9 Cooper ME, Yarbrough DR, Zone-Smith L, et al. Application of field triage guidelines by out of hospital personnel: is mechanism of injury a valid guideline for patient triage? American Surgeon 1995;61:363-71.

10 Knopp R, Yanagi A, Kallsen G, et al. Mechanism of injury and anatomic injury as criteria for out of hospital trauma triage. Ann Emerg Med 1988; 17:895-902.

11 Esposito TJ, Offner PJ, Jurkovich GJ, et al. Do out of hospital trauma center triage criteria identify major trauma victims? Archives of Surgery 1995; 130:171-6.

12 Lowe DK, Oh GR, Neely KW, et al. Evaluation of injury mechanism as a criterion in trauma triage. Am J Surg 1986;152:6-10.

13 Kane G, Engelhardt R, Celentano J, et al. Empirical development and evaluation of out of hospital trauma triage instruments. J Trauma 1985;25(6):482-9.

14 Long WB, Bachulis BL, Hynes GD. Accuracy and relationship of mechanisms of injury, trauma score, and injury severity score in identifying major trauma. Am J Surg 1986;151:581-4.

15 Newgard CD, Lewis RJ, Jolly BT. Use of out-of-hospital variables to predict severity of injury in pediatric patients involved in motor vehicle crashes. Ann Emerg Med 2002;39:481-91.

16 Henry MC, Hollander JE, Alicandro JM, et al. Incremental benefit of individual American College of Surgeons' trauma triage criteria. Acad Emerg Med, 1996 Nov, 3(1 1):992-1000.

17 Henry MC, Alicandro JM, Hollander JE, et al. Evaluation of American College of Surgeons trauma triage criteria in a suburban and rural setting. Am J Emerg Med, 1996 Mar, 14(2): 124-9.

18 Fries GR, McCalla G, Levitt MA, et al. A prospective comparison of paramedic judgment and the trauma triage rule in the prehospital setting. Ann Emerg Med 1994;24:885-9.

19 Ramenofsky ML, Ramenofsky MB, Jurkovich GJ, et al. The predictive validity of the pediatric trauma score. J Trauma 1988;28:1038-42.

20 Norcross ED, Ford DW, Cooper ME, et al. Application of American college of surgeons' field triage guidelines by pre-hospital personnel. J Am Coll Surg 1995; 181:539-44.

21 Bond RJ, Kortbeek JB, Preshaw RM. Field trauma triage: combining mechanism of injury with the prehospital index for an improved trauma triage tool. J Trauma 1997;43:283-7.

22 West JG, Murdock MA, Baldwin LC, et al. A method for evaluating field triage criteria. J Trauma 1986;26:655-9.

23 Simmons E, Hedges JR, Irwin L, et al. Paramedic injury severity perception can aid trauma triage. Ann Emerge Med 1995;26:461-8.

24 Qazi K, Wright MS, Kippes C. Stable pediatric blunt trauma patients: Is trauma team activation always necessary? J Trauma 1998;45:562-4.

25 Qazi K, Kempf JA, Christopher NC, et al. Paramedic judgment of the need for trauma team activation for pediatric patients. Acad Emerg Med 1998;5:1002-7.

26 Shatney Ch, Sensaki K. Trauma team activation for 'mechanism of injury' blunt trauma victims: time for a change? J Trauma 1994;37:275-82.

27 Simon BJ, Legere $\mathrm{P}$, Emhoff $\mathrm{T}$, et al. Vehicular trauma triage by mechanism: avoidance of the unproductive evaluation. J Trauma 1994;37:645-9.

28 Phillips JA, Buchman TG. Optimizing prehospital triage criteria for trauma team alerts. J Trauma 1993;34:127-32 
29 Kohn MA, Hammel JM, Bretz SW, et al. Trauma team activation criteria as predictors of patient disposition from the emergency department. Acad Emerg Med 2004; 11:1-9.

30 McDermott FT, Rosenfeld JV, Laidlaw JD, et al. Evaluation and management of road trauma survivors with brain injury and neurologic disability in Victoria. J Trauma 2004;56:137-49.

31 Chestnut RM, Marshall LF, Klauber MR, et al. The role of secondary brain injury in determining outcome from severe head injury. J Trauma 1993:34:216-22.

32 Tasker RC, Gupta S, White DK. Severe head injury in children: geographical range of an emergency neurosurgical practice. Emerg Med J 2004;21:433-7.

33 The Abbreviated Injury Scale, 1990 Revision, Update 98. Association for the Advancement of Automotive Medicine, 2001.

34 Gilbert EH, Lowenstein SR, Koziol-McLain J, et al. Chart reviews in emergency medicine research: where are the methods? Ann Emerg Med 1996;27:305-8.

35 Breiman L, Freidman JH, Olshen RA, et al. Classification and regression trees. New York: Chapman \& Hall, 1984

36 Efron B. The jackknife, the bootstrap and other resampling plans. In:The regional conference series in applied mathematics. Philadelphia: Society for Industrial and Applied Mathematics, 1982.

37 Stone $M$. Cross-validatory choice and the assessment of statistical predictions. J Roy Statist Soc Ser B 1974;36:111-47.

38 Geisser S. The predictive sample reuse method with applications. J Amer Statist Assoc 1975;70:320-8

39 Samplais JS, Denis R, Frechette P, et al. Direct transport to tertiary trauma centers versus transfer from lower level facilities-impact on mortality and morbidity among patients with major trauma. J Trauma 1997:43:288-96.

40 Young JS, Bassam D, Cephas GA, et al. Interhospital versus direct scene transfer of major trauma patients in a rural trauma system. Am Surg 1998:64:88-91.
41 Newgard CD, Hedges JR, Arthur $M$, et al. The benefit of and factors associated with emergency department transfer of head-injured patients for higher level of care in a rural trauma system. [Abstract] SAEM Western Regional Conference, Scottsdale, AZ April, 2003.

42 Baxt WG, Upenieks V. The lack of full correlation between the injury severity score and the resource needs of injured patients. Ann Emerg Med 1990;19:1396-1400

43 Bazzoli GJ, Madura KJ, Cooper GF, et al. Progress in the development of trauma systems in the United States, results of a national survey. JAMA 1995:273:421-2.

44 Norwood SH, McAuley CE, Berne JD, et al. A prehospital Glasgow Coma Scale score $\leqslant 14$ accurately predicts the need for full trauma team activation and patient hospitalization after motor vehicle collisions. J Trauma 2002;53:503-7.

45 Champion HR, Sacco WJ, Copes WS, et al. A revision of the trauma score. J Trauma 1989;29:623-9.

46 Mullins RJ, Veum-Stone J, Helfand M, et al. Outcome of hospitalized injured patients after institution of a trauma system in an urban area. JAMA 1994:271:1919-24.

47 Mullins RJ, Mann NC, Hedges JR, et al. Preferential benefit of implementation of a statewide trauma system in one of two adjacent states. J Trauma 1998;44:609-17

48 Hulka F, Mullins RJ, Mann NC, et al. Influence of a statewide trauma system on pediatric hospitalization and outcome. J Trauma 1997:42:514-19.

49 Mullins RJ, Mann NC. Population-based research assessing the effectiveness of trauma systems. J Trauma 1999;47:S59-66.

50 Jurkovich GJ, Mock C. Systematic review of trauma system effectiveness based on registry comparisons. J Trauma 1999:47:S46-55.

51 Mann NC, Mullins RJ, Mackenzie EJ, et al. Systematic review of published evidence regarding trauma system effectiveness. J Trauma 1999;47:S25-33.

52 Nathens AB, Jurkovich GJ, Cummings $P$, et al. The effect of organized systems of trauma care on motor vehicle crash mortality. JAMA 2000;283:1990-4. 